\title{
The Investigation of Validity and Reliability of Job-Satisfaction Questionnaire
}

\author{
Maryam Afsar ${ }^{1 *}$
}

\section{ABSTRACT}

Purpose: This study has been done with the aim of seeking norms and investigating reliability and validity of job-satisfaction inventory and in line with preparation of appropriate tools to evaluate job satisfaction. Method: in form of a periodical study 2760 people were selected from the staffs of five variety profession of managers, bosses, employee, salesclerks and workers by categorical sampling and they filled the job-satisfaction inventory which contained sixty statements. Also to investigate the validity of the structure factorial discovery and confirmatory analysis and to investigate reliability Cronbach's alpha and to analyze the data SPSS 19 and AMOS 18 were used. Findings: the results of data analysis represented 24 options from the 60 early raw options had the respective attribute and value and incorporated in final version. Moreover with cyclical varimax, and additive variance of $48.12 \%$ and Kaser-Meyer-Olkin index of $67 \%$, three factors of individuality, organizational and work nature were discovered. Furthermore the results of data analysis showed that the higher amount of variance of jobsatisfaction were devoted respectively, regarding distinction of lines, to organization(3.47), south dairy(3.41),west dairy(3.39), fleshy(3.38), drinking(3.38), Tehran dairy(3.35), north dairy(3.35), ice cream(3.35) and trade(3.32). Conclusion: with respect to measured indices of reliability and validity, the psychological features of job-satisfaction questionnaire were all reported appropriate and can be used as a reliable and valid tool to measure staffs' job satisfaction.

Keywords: Job Satisfaction, Validity, Reliability.

Perhaps it can be said that among all of concepts that management and organizational behavior experts have investigated in various situations, job satisfaction has been one of the most important research fields. The reason of this importance can be investigated from two aspects. First it is because of the important role it plays in improving and development of organization, sanitation and health of workforce. Second it is because of concept of job satisfaction itself that beside having various definitions, is the central meeting point of many scientific fields like

\footnotetext{
${ }^{1}$ MA psychometric in central Tehran of azad university, Tehran, Iran

*Responding Author

(C) 2016 I M Afsar; licensee IJIP. This is an Open Access Research distributed under the terms of the Creative Commons Attribution License (http://creativecommons.org/licenses/by/2.0), which permits unrestricted use, distribution, and reproduction in any Medium, provided the original work is properly cited.
} 


\section{The Investigation of Validity and Reliability of Job-Satisfaction Questionnaire}

psychology, management, sociology, and even economy and politics. Job satisfaction is one of the important factors that should be considered in economic development since it has played an important role in job success and has caused increasing of efficiency and individual satisfaction (ShafiAbadi, 2002).

From the historical point of view job satisfaction has been investigated since 1920s and lots of theories have been proposed for it. The variety of its approaches and theories could be accounted for by three main points of view which had formed in 1920 and 1930 and more than anything else had affected the concept of job satisfaction. These three views are: 1. Human relations movement: 2. Workers unions: 3. Development view or nature of work (korman, 1999). Job satisfaction typically concerns with staffs' attitude. This notion has various aspects and may represent the general view toward job. Job satisfaction as a set of individual emotions has a dynamic nature, i.e. it will be vanished in the same way and with the same degree it has been appeared. Therefore, to stabilize it, continual attention of managers is necessary (Davies and Strom, 1991).

Everybody in their daily life will be encountered with different subjects that will be considered appropriate or inappropriate by them and they express satisfaction or dissatisfaction in facing and doing them. Job environment too will induce different emotions in individuals that feelings of satisfaction or dissatisfaction are among the most important ones (Lavar, 1997). Theoretically job satisfaction is a set of adaptive and non-adaptive feelings that staffs look at themselves by those feelings. When staffs join the organization, they have with them a set of past wants, needs, and experiences that together make job expectations that are a sign of relation of staffs' new expectations with rewards that that job provides (Davies and Strom, 1370). According to view of Shafiabadi (1997) job satisfaction which is a kind of positive feeling toward work is the outcome of factors like the situation of work environment, job's organizational discipline, the relations prevailing upon work condition, and the effect of cultural factors. Thus it can be stated that job satisfaction is a psychological feeling that is affected by social factors.

Fledman and Arnold (1995) define job satisfaction in a form of a set of positive feelings and tendencies that people have relative to their jobs. Davies and storm have enumerated the advantages of job satisfaction under three efficiencies: manager will become aware of job

satisfaction trends, causes cohesive relationship between employee and organization's higher positions, can be a sign of managers' dependency on staffs' welfare and is a useful method to determine some of the instructional needs and usually provides staffs with opportunity to express their feelings towards the working method of bosses (Jafari, 1381).

The relationship between job satisfaction and performance of people in specialized, administering, and managing positions is strong and direct (robinz, 1986). Those staffs that have poor performance didn't have the right enough feeling of competence and performance and probably have lower receptions and it is common that it would have a negative effect on their job 


\section{The Investigation of Validity and Reliability of Job-Satisfaction Questionnaire}

satisfaction (Fledman, 1995). There is a positive relationship between job satisfaction and positive efficiency meaning that those who have higher internal satisfaction toward their job are more effortful at least in some part of their work conditions (Davies and Storm, 1370). Arjis's studies (1976) showed that more effortful workers are more satisfied and more loyal to their organizations.

Job satisfaction has opposite relationship with the extent of staff's movements and this relation is stronger than that of job satisfaction with number of absences. Satisfied workforce, because of decrease in absences, will result in increase of efficiency (Fledman, 1999). The relationship between job satisfaction and life satisfaction has been reported to be strong (Rezaeian, 1979). The results of studies show that keeping and maintaining the work force, needs analysis, understanding of wants, motives, provision of job satisfaction and improving of mood and promotion of staffs' psychological sanitation should be highly considered. Considering these cases along with inducing positive attitude in staffs relative to work and customer and taking appropriate steps in conforming individual goals (staffs' job satisfaction) to organizational goals is an important step for efficiency and efficacy of organizations. Therefore, we should recognize the appropriate ways in developing staffs' job satisfaction so that with moving in that line, we easily provide them with necessary motivation (Hoseinizadeh, 1379).

In this line shortage of appropriate tools to evaluate the index of staffs' satisfaction is highly felt as a standard for organizing of programs of macro organizations. With respect to what we have seen and with regard to current shortages in realm of psychological tools we intend to investigate psychological indices of one Iranian made questionnaire. We hope that the findings of this research can help the industrial and productive centers to reach their great goals.

\section{METHOD}

This research is a kind of periodical analysis with aim of standardizing job-satisfaction questionnaire that had done on a sample of 2760 persons by field finding. Sampling method in this study was categorical and multi-phase based on expertise levels. Criterion of selecting one person in this study was formal or conventional membership or based on a contract, and criterion of exit from study was not having intention of active participation in research process. After data collection, analyses were done generally. Also demographic information of subjects was used as complementary data.

\section{Size Of Sample}

With respect to nature of this research and with regard to type of research design, size of sample in studies like this will be estimated as 10 subjects or 100 subjects in appropriate condition relative to each index or option of questionnaire. With regard to 24 options of marital satisfaction questionnaire, the size of sample of this research was considered as 2400 persons. With respect to $15 \%$ relative estimation of emission of subjects from sample, 360 persons were added to sample size and at last 2760 questionnaires were distributed between subjects. 


\section{Ethical Principles}

Conscious satisfaction in this research has been obtained without any compulsion; threading, stimulation and temptation, and people's refusal of agreement and of continuing to participate in research process were respected. It has been tried not to divert from subjects' religious and cultural positions and norms and participants in all phases of research were protected with regard to their generosity, respect, mental and physical well-being so that doing of research would not make any interruption and disorder in the process of medical control of subjects. To ensure moral norms, subjects of waiting list after finishing of research, were periodically presented with five sessions of mother-child interaction therapy.

\section{Statistical Analysis}

To analyze the data in this study descriptive statistics method (percent, mean, and standard deviation) and inferential statistics (factorial discovery and confirmatory analysis) were used. To statistically analyze the data, SPSS 18 and AMOS 18 software were used. Also demographic information of subjects was used as complementing data. To investigate the validity two methods of content and face and to investigate reliability, internal correlation and corn Bach Alpha coefficient were applied.

\section{RESULTS}

Gender distribution of sample of 2760 people, was in form of 1781 men (65\%) and 959 women (35\%). Men's average age was 37.12 with range of 12.3 and women's average age was 29.54 with range of 7.21. The extent of job satisfaction in multiple centers is represented in table1.

Table1: average distribution of marital satisfaction in 9-section units.

\begin{tabular}{|l|l|l|l|l|l|l|}
\hline $\begin{array}{l}\text { Organizational } \\
\text { level }\end{array}$ & managers & supervisors & $\begin{array}{l}\text { experts } \\
\text { and } \\
\text { employees }\end{array}$ & workers & & $\begin{array}{l}\text { average of } \\
\text { job- } \\
\text { satisfaction }\end{array}$ \\
\hline north dairy & 3.56 & 3.46 & 3.31 & 3.12 & 3.31 & 3.35 \\
\hline Tehran dairy & 3.53 & 3.30 & 3.38 & 3.20 & 3.36 & 3.35 \\
\hline west dairy & 3.67 & 3.52 & 3.43 & 3.17 & 3.19 & 3.39 \\
\hline south dairy & 3.81 & 3.41 & 3.40 & 3.17 & 3.24 & 3.41 \\
\hline fleshy & 3.64 & 3.64 & 3.41 & 3.15 & 3.25 & 3.38 \\
\hline ice cream & 3.51 & 3.49 & 3.43 & 3.13 & 3.19 & 3.35 \\
\hline drinks & 3.57 & 3.51 & 3.22 & 3.39 & 3.21 & 3.38 \\
\hline trading & 3.51 & 3.43 & 3.45 & 3.13 & 3.05 & 3.32 \\
\hline organization & 3.68 & 3.43 & 3.40 & 3.12 & 3.37 & 3.47 \\
\hline
\end{tabular}

In diagram 1 average distribution of job satisfaction is presented. 


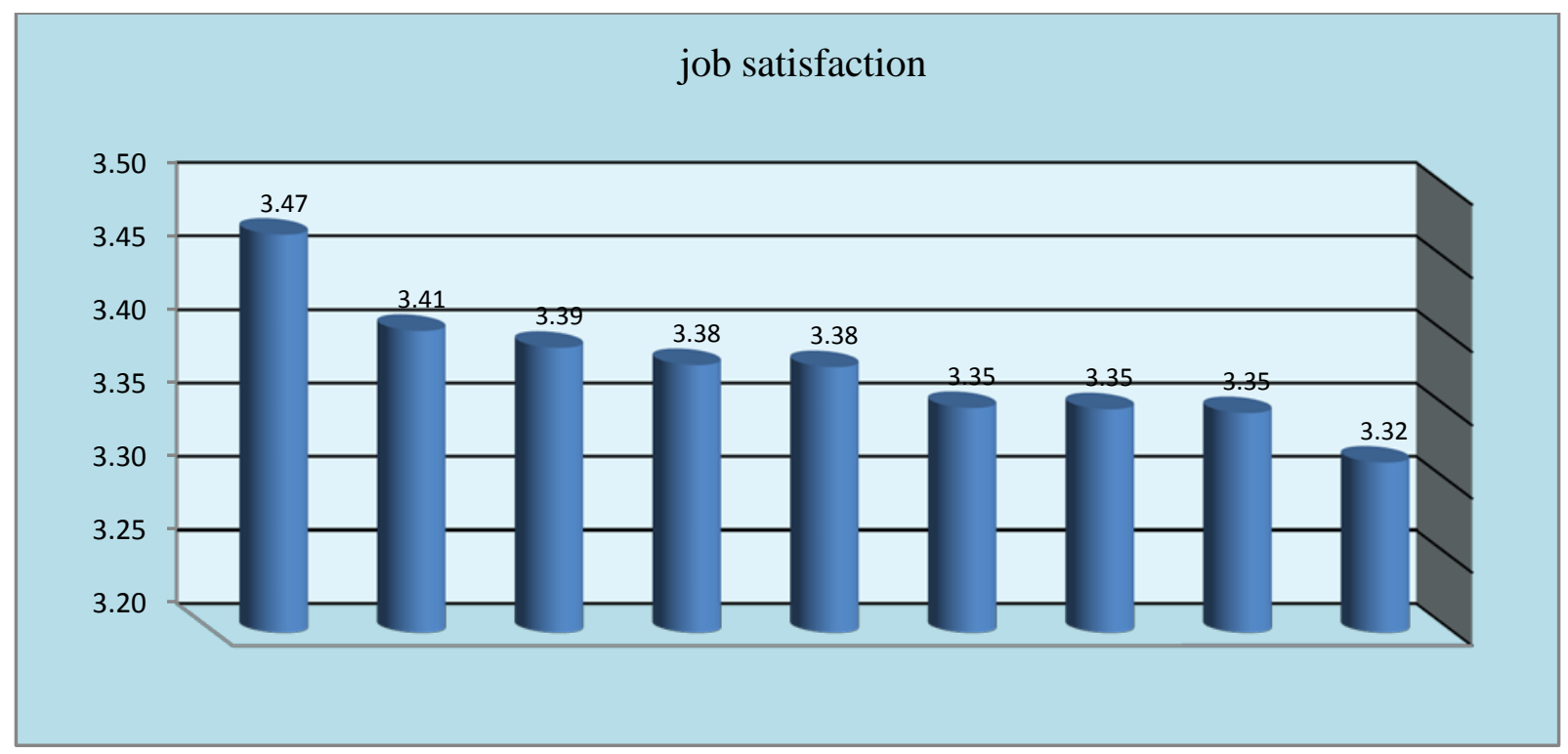

Diagram1: extent of job satisfaction

In table 3 correlations is represented under domains of three main indices together.

Table 3: correlation under sections of questionnaire

\begin{tabular}{|l|l|l|l|}
\hline sub factors & individuality & organizational & work nature \\
\hline individuality & $0.274^{*}$ & $0.212^{*}$ & - \\
\hline organizational & $0.196^{*}$ & - & $0.217^{*}$ \\
\hline work nature & - & $3.21^{* *}$ & $2.414^{*}$ \\
\hline
\end{tabular}

*CL: 0.05, **CL: 0.01

As it has been considered to investigate validity of the questionnaire, content validity method was used. Thus with respect to experts opinion 60 questions were developed. Then some of the experts tested them for their briefness and cohesion based on CVR and CVI indices. The result of this analysis of decreasing of inventory questions based on factorial discovery analysis by anti-image matrix was 24 options of questionnaire. Through Varimax rotation, three factors with accumulative frequency of $48.12 \%$ and Kaser-Meyer-Olkin index of $64 \%$ were discovered. Three respective factors based on researcher's view were: individual factors, organizational factors and work nature. Furthermore average approximate squares (RMSEA) was lower than 0.05 and amounts of higher than 0.7 were obtained for accuracy indices of three discovery options that represents model's suitability index and its efficiency. Reliability of questionnaire by Cronbach's alpha was 89\% which was considered suitable for its reliability.

\section{DISCUSSION}

This research was a kind of study to investigate reliability and validity of a researcher-made questionnaire that was done to investigate job satisfaction index in staffs of management and service sections. The results of research showed that this job-satisfaction questionnaire had 
significant reliability and validity. Moreover to derive key factors, three factors of individuality, organizational and work nature were derived by factorial discovery analysis. Altogether the results showed that job-satisfaction questionnaire has appropriate reliability and validity. This study has done based on importance of concept of job satisfaction. Job satisfaction means to love different tasks of each job, conditions under which the job is done and the reward that is paid for doing that job. Therefore, it is a complex and multi-dimension concept that is related to different psychological, social and physical factors. Not just one factor can lead to job satisfaction but it is a combination of different factors that cause the employed person feels satisfaction at one specific moment from his or her work and would say to him and her that they are satisfied with their job and enjoy it. People with emphasizing different factors like income, job's social values, work condition and its environment and job interest in different times would express their satisfaction differently. Therefore, job satisfaction is an emotional response that obtains by individual's understanding of this fact that their job provides their respective job values or allows them to meet these values. Besides, job satisfaction depends on concordance of these values with personal needs (Shertoz, 1371). Some studies have been done in this regard. For example, Hoseinizadeh (1379) had investigated the effective factors on job satisfaction of employees of teacher training university. The result of his research showed that personal information has no effect on the way of answering inventory questions. In other words employees have different personal features but they have similar views and opinions and the factors that lead to their job satisfaction or dissatisfaction has same effect on them. Ashraf Arabi(1377) investigated the inducing factors of job satisfaction in staffs of national rehabilitation center by descriptive method. Results represented that 47 percent were satisfied with their jobs, 63 percent were indifferent and 19.4 percent were dissatisfied. For example results of Yusefpour's(1377) study with subject of efficiency of overtime work income on job satisfaction of railway staffs represented that overtime work plan had been effective in job satisfaction and efficiency of organization.

\section{ACKNOWLEDGMENTS}

The author appreciates all those who participated in the study and helped to facilitate the research process.

\section{Conflict Of Interests}

The author declared no conflict of interests.

\section{REFERENCES}

Alavi, S. A. (1381). Psychology of management and organization behavior, Fifth edition, Tehran: national management educational center.

Dad, S.(1371). Investigation of effects of three instructional programs of intersrvice of staffs of Iran petroleum company and the effect of it on efficiency, success and job satisfaction of them , Soheila Dad, 1371, dissertation of Tehran university 
Dios, Kit, Newstorm, John; Human behavior in work, translated by Tousi, Mohammad Ali, national management educational center, 1370

Feldman, D. C., (1995). Organizational behavior. Edt, New York MC Graw. Hill.

Hoseinizadeh, A. A.(1379). Investigation of effective factors in job satisfaction of staffs, MA dissertation, Tehran: Teacher training university.

Jafari, M.(1381). Investigation of effect of organizational culture on job satisfaction of police university staffs, MA dissertation, Teacher training university.

Khodayarifard, mohammad, parand, Akram, (1386). Anxiety and ways to treat it. Tehran university publications, Tehran/ Iran

Korman, A.(1378). Organizational and industrial psychology, translated by Shekarkan, Hosein, Tehran: Roshd Publications

Lawler, Edward E. (1997). Job attitude an employee motivation: Theory research and practice. Personel psychology. London

Shafi Abadi, A. (1376). Educational and professional guideline, Payam nour university publications

Shafi Abadi, A. (1381). Theories of job directions and consultations and theories of job selection, Tehran , Roshd Publications.

Shertoz, Eiros, Investigation and planning of educational and professional life, translated by Zandipour, Tayebeh, Tehran: Ferdos Publication, 1371

How to cite this article: M Afsar (2016) The Investigation of Validity and Reliability of JobSatisfaction Questionnaire, International Journal of Indian Psychology, Volume 3, Issue 3, No. 5, DIP: $18.01 .087 / 20160303$ 